\title{
Protein kinase $A$ is a common negative regulator of Hedgehog signaling in the vertebrate embryo
}

\author{
Matthias Hammerschmidt, Mark J. Bitgood, and Andrew P. McMahon ${ }^{1}$ \\ Department of Molecular and Cellular Biology, The Biolabs, Harvard University, Cambridge, Massachusetts 02138 USA
}

\begin{abstract}
Midline signaling by Hedgehog $(\mathrm{Hh})$ family members has been implicated in patterning the vertebrate embryo. We have explored the potential regulatory role of cAMP-dependent protein kinase $A$ (PKA) in these events. Zebrafish embryos injected with RNAs encoding Sonic hedgehog (Shh), Indian hedgehog (Ihh), or a dominant-negative regulatory subunit of PKA, PKI, have equivalent phenotypes. These include the expansion of proximal fates in the eye, ventral fates in the brain, and adaxial fates in somites and head mesenchyme. Moreover, ectopic expression of PKI partially rescues somite and optic stalk defects in no tail and cyclops mutants that lack midline structures that normally synthesize Shh. Conversely, all cell types promoted by ectopic expression of hhs and PKI are suppressed in embryos injected with RNA encoding a constitutively active catalytic subunit of PKA (PKA*). These results, together with epistasis studies on the block of ectopic Hh signaling by PKA ${ }^{\star}$, indicate that PKA acts in target cells as a common negative regulator of Hedgehog signaling.
\end{abstract}

[Key Words: Sonic hedgehog; Indian hedgehog; protein kinase A; midline signaling; zebrafish]

Received December 20, 1995; revised version accepted February 2, 1996.

Members of the hedgehog $(h h)$ gene family encode signaling proteins involved in induction and patterning processes in vertebrate and invertebrate embryos. In vertebrates, hhs constitute a multigene family. Sonic hedgehog (Shh), which has received most of the experimental attention, has been isolated from mouse (Echelard et al. 1993; Chang et al. 1994), chick (Riddle et al. 1993), rat (Roelink et al. 1994), Xenopus (Ekker et al. 1995), and zebrafish (Krauss et al. 1993). The early expression is limited to the notochord, the floor plate and its anterior extension in the brain, and the zone of polarizing activity (ZPA) in the posterior mesenchyme of the limb bud. All of these sites have been shown to act as organizing centers patterning neighboring tissues by the secretion of morphogenetic signals (e.g., Saunders and Gasseling 1983; Brand-Saberi et al. 1993; Pourquie et al. 1993; Yamada et al. 1993). Recent evidence indicates that Shh is involved in these interactions.

For example, ectopically expressed Shh leads to a ventralization of large regions of the mid- and hindbrain in mouse and zebrafish, as revealed by the dorsally expanded expression pattern of $H N F-3 \beta$ and its zebrafish homolog axial (Echelard et al. 1993; Krauss et al. 1993). In explants of intermediate neuroectoderm at spinal cord levels, Shh protein induces, in a dose-dependent fashion, floor plate, and motor neuron development (Martí et al.

\footnotetext{
${ }^{1}$ Corresponding author.
}

1995a; Roelink et al. 1995; Tanabe et al. 1995). In explants taken at midbrain and forebrain levels, Shh also induces the appropriate ventrolateral neuronal cell types, dopaminergic (Heynes et al. 1995; Wang et al. 1995) and cholinergic (Ericson et al. 1995) precursors, respectively. In chick somites (Johnson et al. 1994) and mouse presomitic explants (Fan et al. 1995), Shh promotes the expression of sclerotome-specific markers like Pax1 and Twist at the expense of the dermamyotomal marker, Pax3. Together with Wnt signals, Shh also promotes myotomal development (Münsterberg et al. 1995). Furthermore, when ectopically expressed in the anterior region of chick limb buds, Shh leads to a mirror-image duplication of digits similar to transplants of the ZPA (Riddle et al. 1993; Chang et al. 1994).

Less is known about the properties of other vertebrate Hedgehogs (Hhs). In the mouse, two additional Hh genes have been identified. Indian hedgehog (Ihh) is expressed in the growth zone of the developing cartilage and in intestinal epithelium, whereas Desert hedgehog $(D h h)$ is expressed by Sertoli cells in the testes (Bitgood and McMahon 1995). Mutational studies have demonstrated that $\mathrm{Dhh}$ is required for normal spermatogenesis (Bitgood et al. 1996). Other $h$ h genes isolated from Xenopus and zebrafish are expressed earlier, beginning with the onset of gastrulation, and exhibit distinct and partially overlapping expression patterns (Ekker et al. 1995a,b). One of these genes, tiggy-winkle hedgehog (twhh) is coexpressed with shh in the ventral central nevous system 
(CNS), and like shh, has been shown to promote proximal cell fate in the zebrafish eye (Ekker et al. 1995b).

In Drosophila, only a single $h h$ gene has been identified and shown to have a pivotal role in the regulation of many aspects of larval and adult pattern formation. For example, specific cell fates in the larval cuticle appear to be regulated by concentration-dependent Hh signaling (Heemskerk and DiNardo 1994). In the eye imaginal disc, Hh produced by newly differentiating photoreceptors regulates the movement of the morphogenetic furrow and, therefore, recruitment of uncommitted cells to differentiated fates (Heberlein et al. 1993; Ma et al. 1993). In the leg and wing imaginal discs, Hh produced by cells in the posterior compartment regulates gene expression at the compartment boundary, which is essential for normal patterning and outgrowth of these appendages (e.g., Basler and Struhl 1994; Tabata and Kornberg 1994; Fietz et al. 1995; Ingham and Fietz 1995).

Drosophila studies have identified several genes that appear to mediate Hh signaling or are targets of the $\mathrm{Hh}$ signaling pathway (for review, see Forbes et al. 1993; Perrimon 1995), although the Hh receptor itself has not been identified. The transmembrane protein Patched, the serine-threonine kinase Fused, and the zinc-finger protein Cubitus interruptus are all involved in the intracellular regulation of $\mathrm{Hh}$ signaling in the responding cells (Ingham et al. 1991, 1993). Moreover, several recent studies point to a role for cAMP-dependent protein kinase $\mathrm{A}$ (PKA) as a regulator of $\mathrm{Hh}$ signaling. Loss of PKA activity leads to the cell-autonomous, Hh-independent, transcriptional activation of $\mathrm{Hh}$ target genes patched, wingless, and decapentaplegic) in eye, leg, and wing imaginal discs (Jiang and Struhl 1995; Lepage et al. 1995; Li et al. 1995; Pan and Rubin 1995; Strutt et al. 1995; for review, see Kalderon 1995; Perrimon 1995). Thus, PKA acts as a negative regulator of the Hh signaling pathway in Drosophila.

The mechanism by which $\mathrm{Hh}$ signals are transduced in vertebrates is less well understood. However, there is evidence that PKA may be involved, as a variety of drugs that stimulate PKA activity block Shh-mediated induction of Pax-1 in somite explants and tyrosine hydroxylase-expressing neurons in mesencephalic explants (Fan et al. 1995; Heynes et al. 1995). We have explored the role of $\mathrm{Hh}$ and PKA signaling in patterning the zebrafish embryo. Our experiments demonstrate that suppression of PKA activity mimicks Hh-specific inductions in many different Hh-responsive cells, whereas constitutive PKA activity blocks the effects of endogenous and ectopic $\mathrm{Hh}$ signaling. Thus, PKA acts in target cells as a common negative regulator of $\mathrm{Hh}$ signaling pathways in vertebrate embryogenesis.

\section{Results}

Inhibition of PKA and ectopic expression of hhs leads to similar alterations in eye patterning

Expression of $s h$ at the ventral midline of the forebrain has been implicated in patterning the vertebrate eye (Ek- ker et al. 1995b; Macdonald et al. 1995). Proximal cell fates, which appear to depend on Shh signaling, are expanded in zebrafish embryos ectopically expressing shh. Concomitantly, distal retinal fates are reduced, resulting in a small eye phenotype (Ekker et al. 1995b; Macdonald et al. 1995). To determine whether Shh may act by regulating the activity of PKA, we compared the phenotype generated in zebrafish embryos ectopically expressing a dominant-negative form of PKA, PKI, with those induced by ectopically expressed shh, and several other vertebrate $h h$ family members.

In the inactive state, PKA consists of a tetramer composed of two identical regulatory subunits and two identical catalytic subunits. Binding of cAMP by the regulatory subunits leads to dissociation of the complex, release of the catalytic subunits, and as a result, phosphorylation of target proteins. Clegg et al. (1987) have reported that CAMP-mediated activation of PKA is effectively blocked in tissue culture cells expressing a regulatory subunit containing a point mutation in the cAMP-binding domains. Thus, injection of RNA encoding this subunit into the zebrafish embryo provides a strategy by which endogenous PKA activity may be inhibited specifically.

Embryos injected with RNAs encoding zebrafish Shh, mouse Shh and Ihh, and mouse PKI display a similar reduced eye development. The frequency and severity of the phenotype is highest in embryos ectopically expressing zebrafish shh (158 of 169; 93\%), mouse Ihh (104 of $120 ; 87 \%)$ and PKI $(105$ of $130 ; 81 \%)$, but weaker for those expressing mouse $\operatorname{Shh}(43$ of $85 ; 51 \%$ ) (Fig. 1A-E). Injection of a lac $Z$ control RNA gave no phenotype 10 of 105).

Previous reports (Ekker et al. 1995b; Macdonald et al. 1995) have demonstrated that the small eye phenotype is the result of an expansion of the pax 2 and a reduction of the pax6 expression domain. pax 2 is normally expressed proximally in the presumptive optic stalk, adjacent to a domain of shh expression at the ventral midline of the forebrain, whereas pax6 expression is restricted to more distal regions of the eye primordia (Krauss et al. 1991; Fig. 1F,I). As with ectopic shh expression, ectopic expression of $I h h(50$ of $52,96 \%)$ and PKI $(48$ of $73,66 \%)$ leads to expansion of the pax2 expression domain (Fig. 1G,H), whereas pax6 expression is substantially reduced (Thh: 16 of $39,41 \%$; PKI: 38 of $49,76 \%$ ) (Fig. 1J,K). Therefore, ectopic expression of PKI mimics the phenotypic consequences of ectopic $h h$ expression in the developing eye. Moreover, it is clear that $I h h$, whose expression is normally restricted to the gut and cartilage (Bitgood and McMahon 1995), phenocopies the effects of Shh. It is therefore, likely that different $h h$ family members share similar signaling properties.

In cyclops (cyc; Hatta et al. 1991b) mutant zebrafish embryos, which lack shh expression in the ventral forebrain, the expression of pax2 in the region of the optic stalk is reduced strongly at early somite stages (Krauss et al. 1993) and absent completely by early pharyngula stages (Fig. 1L,M). Thus, the optic stalk deficiencies in cyc mutants might result from the lack of $s h h$ expression 


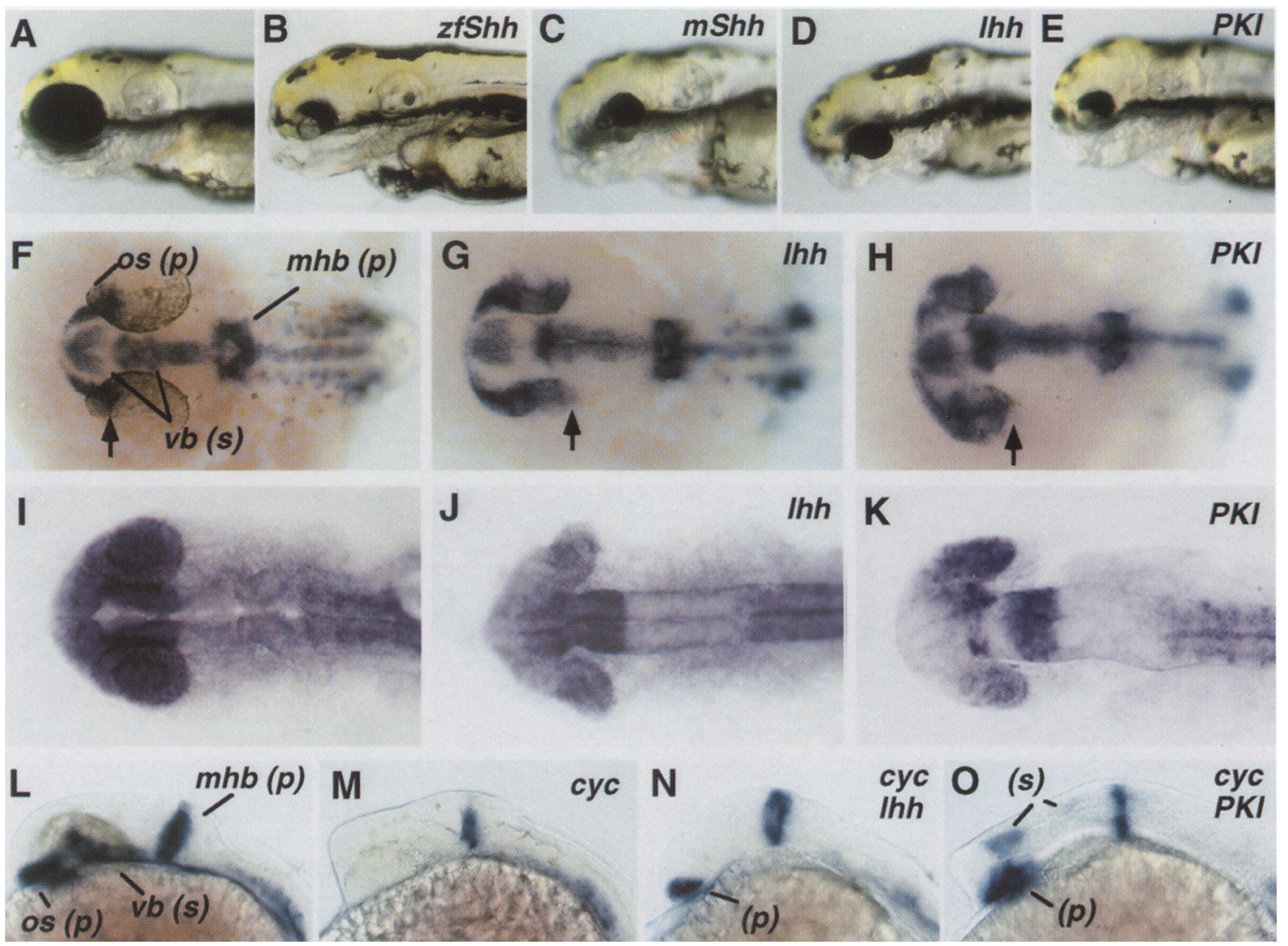

Figure 1. The effect of expression of hh family members and PKI on eye patterning in wild-type and cyc mutant embryos. $(A, F, I, L)$ Control embryos. Embryos in all other panels were injected with the indicated RNAs. $(A-E)$ Four-day-old larvae, lateral view of head. $(F-K)$ Twenty-six-hour-old wild-type embryo, dorsal view of head. $(F-H)$ Expression of pax2 $(p)$, distal expansion in eye primordia (arrow), and shh $(s) .(I-K)$ Expression of pax6. $(L-O)$ Twenty-six-hour-old embryos, lateral view of head; expression of pax2 and shh. $|M-O| c y c$ mutants. Rescued pax2 expression in optic stalk $(p)$, ectopic shh expression in dorsal regions of the midbrain $(s)$ (cf. with Fig. 2F). (os) Optic stalk; (mhb) midbrain-hindbrain boundary; (vb) ventral base.

(Macdonald et al. 1995). In agreement with this model, injection of RNA encoding Ihh and PKI partially rescues pax2 expression in cyc mutants (Ihh: 7 of $14,50 \%$; PKI: 9 of $19,47 \%$ ) (Fig. $1 \mathrm{~N}, \mathrm{O}$ ), in the absence of any rescue of shh expression in the ventral forebrain. Consequently, embryos still develop a fused eye phenotype. Ectopic shh expression is dectected in PKI-injected cyc mutant embryos, but this is restricted to the dorsal midbrain region, similar to wild-type embryos injected with PKI-encoding RNA (cf. Fig. 10 with Fig. 2F). These experiments suggest that early expression of pax2 in the presumptive optic stalk depends on Hh-mediated inhibition of PKA activity in target cells. Moreover, it is unlikely that the cyc gene product acts downstream of a Hh signal, as both Ihh and PKI rescue pax2 expression.

\section{Regional ventralization of the CNS by PKI and hh signaling}

Ectopic expression of shh in a variety of vertebrate embryos and application of purified Shh to CNS explants has demonstrated that $\mathrm{Shh}$ is a ventralizing factor in the vertebrate CNS (see above). Moreover, the related tran- scriptional regulators, $H N F-3 \beta$ (chick, rat, mouse) and axial (zebrafish), which are normally expressed at the ventral midline of the CNS, are apparent targets of the Shh signaling pathway.

Ectopic expression of zebrafish shh (Krauss et al. 1993) ( 36 of $45,80 \%$; Fig. 2 B) and PKI (153 of $203,76 \%$; Fig. 2D) in the zebrafish embryo gave almost identical results, a dramatic dorsal expansion of axial expression in the midbrain, hindbrain, and anterior spinal cord. Ectopic expression of mouse Ihh (61 of 103, 59\%; Fig. 2C) and mouse Shh (3 of 50,6\%; data not shown) gave a weaker ventralization restricted to the midbrain. Thus, suppression of endogenous PKA activity leads to a strongly ventralized phenotype, closely resembling that generated by the most potent ventralizing signal, zebrafish Shh. PKI expression results in only a slight broadening of the shh expression domain at the diencephalic-midbrain border (32 of $49,65 \%$ ) and a weak activation in the posterior midbrain (2 of $24,8 \%$; Fig. $2 \mathrm{~F})$. Thus, widespread ectopic axial expression presumably reflects a direct activation of the intracellular Shh signaling pathway and not the indirect consequence of induction of an endogenous Shh signal. 


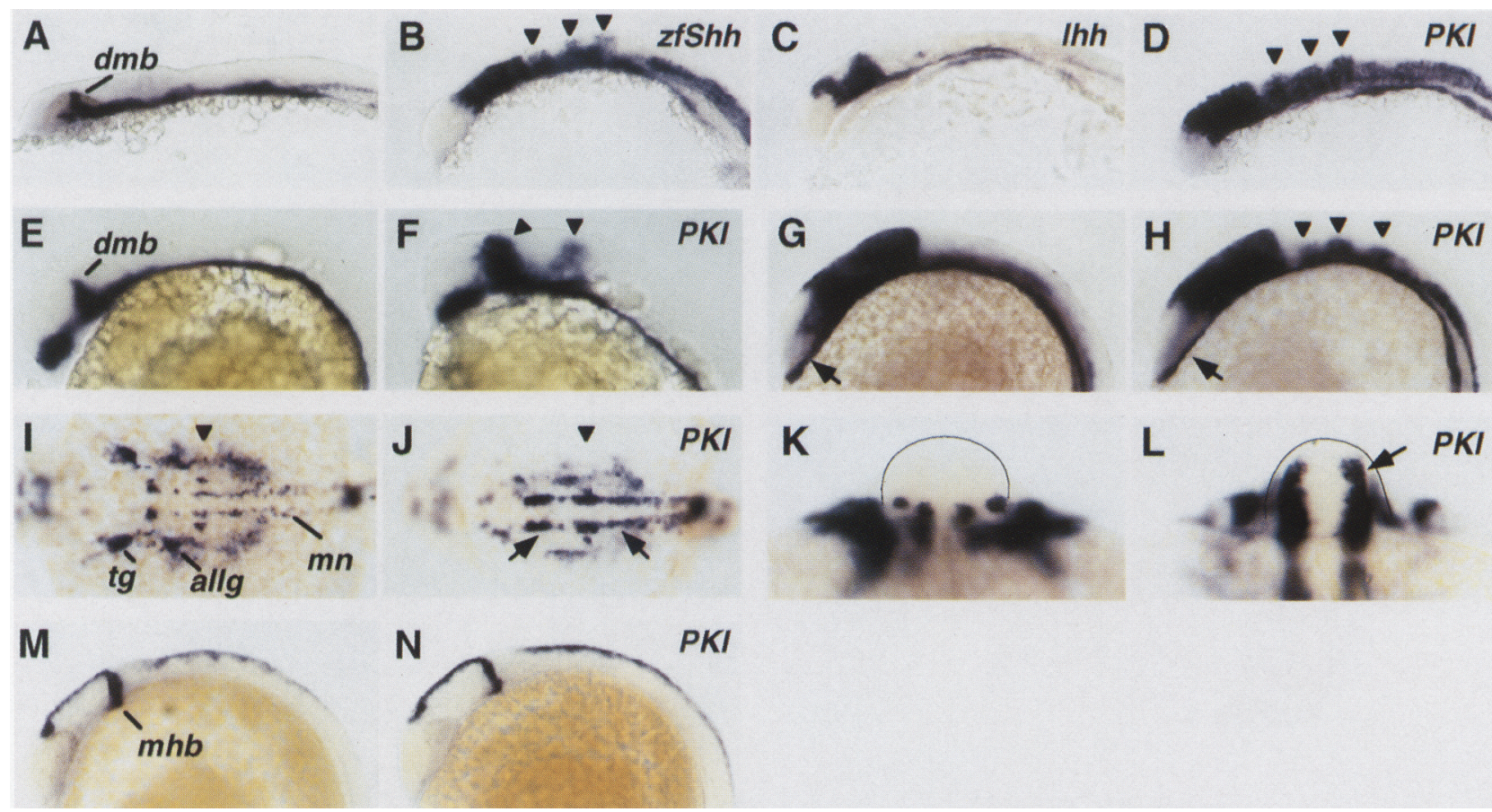

Figure 2. The effect of expression of $h h$ family members and PKI on CNS patterning. $(A-D)$ Expression of axial, 26-hour-old embryos, lateral view of head. The segmented ectopic expression in the hindbrain in $B$ and $D$ is indicated by arrowheads. $(E, F)$ Expression of $s h h$, 26-hour-old embryos, lateral view of head. The expanded expression at the diencephalic-mesencephalic boundary and the ectopic expression in the posterior midbrain is indicated by arrowheads. $(G, H)$ Expression of otx2 and axial, 25-somite stage, lateral view of head. The ectopic expression of axial in the hindbrain is indicated by arrowheads; the expression of otx2 in the ventral forebrain by an arrow. $\mid I-L)$ Expression of is 11, 26-hour-old embryos; $(I, I)$ dorsal view of hindbrain, rostral to the left; $(K, L)$ optical cross-section at level of arrowhead in $M$ and $N$. The neural tube is outlined. Sites of expanded is 1 expression in the hindbrain and the anterior spinal cord are indicated with arrows in $J$ and $L .(M, N)$ Expression of wnt1, 26-hour-old embryos, lateral view of head. (allg) Anterior lateral line ganglion; $(\mathrm{dmb})$ diencephalic-mesencephalic boundary; $(\mathrm{mhb})$ midbrain-hindbrain boundary; (mn) motoneurons; (tg) trigeminal ganglion.

Interestingly, no ectopic induction of axial expression is observed anterior to the position where expression normally terminates, at the diencephalic-midbrain boundary, suggesting that the anterior limit of axial expression is set by a change in the cellular competence to respond to Hh signaling in the forebrain. In support of this conclusion, expression of the homeo domain-containing transcriptional regulator otx2 ( $\mathrm{Li}$ et al. 1994) in the ventral forebrain remains unaltered in embryos exhibiting a strong PKI-induced ventralization of the hindbrain $(0$ of 64 , Fig. $2 \mathrm{H})$. In the hindbrain there is also evidence for differential responsiveness within adjacent rhombomeres, as ectopic expression of both zebrafish shh and PKI leads to a marked segmental organization to the domains of ectopic axial expression (Fig. 2B,D).

To determine whether expression of PKI leads to other aspects of ventralization we examined the expression of isl1, a LIM domain transcription factor expressed in motor neurons (Korzh 1993; Inoue et al. 1994; Appel et al. 1995). Motor neurons arise at ventrolateral positions along the CNS, most likely in response to induction by Shh (Martí et al. 1995a; Roelink et al. 1995). Embryos expressing PKI have a substantial increase (PKI: 23 of 36, $64 \%$; Ihh: 3 of $20,15 \%)($ Fig 2I,J) and a dorsal expansion
(Fig. $2 \mathrm{~K}, \mathrm{~L}$ ) in isl1 expression in the hindbrain and the anterior spinal cord, but no alteration in forebrain expression (data not shown).

In summary, inhibition of PKA mimics several aspects of Shh-mediated ventralization in the CNS. Moreover, the effects are restricted to only those regions that are also responsive to the ectopic expression of $s h h$, and related $h h s$. Although we observe extensive ventralization in the mid- and hindbrain regions, wnt1 expression at the dorsal midline (Molven et al. 1991) (0 of 59, Fig. $3 \mathrm{M}, \mathrm{N})$ is largely unaltered. Thus, the most dorsal cell fates are not suppressed by ventralizing signals in these experiments.

\section{The effects of Ihh and PKI on the patterning of somites}

Shh expression is also implicated in the regulation of somite pattern in the paraxial mesoderm (for review, see Bumcrot and McMahon 1995). For example, sclerotome formation by the somite occurs in response to midline signaling by the notochord (Brand-Saberi et al. 1993; Pourquie et al. 1993), and Shh is able to activate several sclerotome markers in presomitic mesoderm (Johnson et al. 1994; Fan et al. 1995), mimicking the inducing effect 


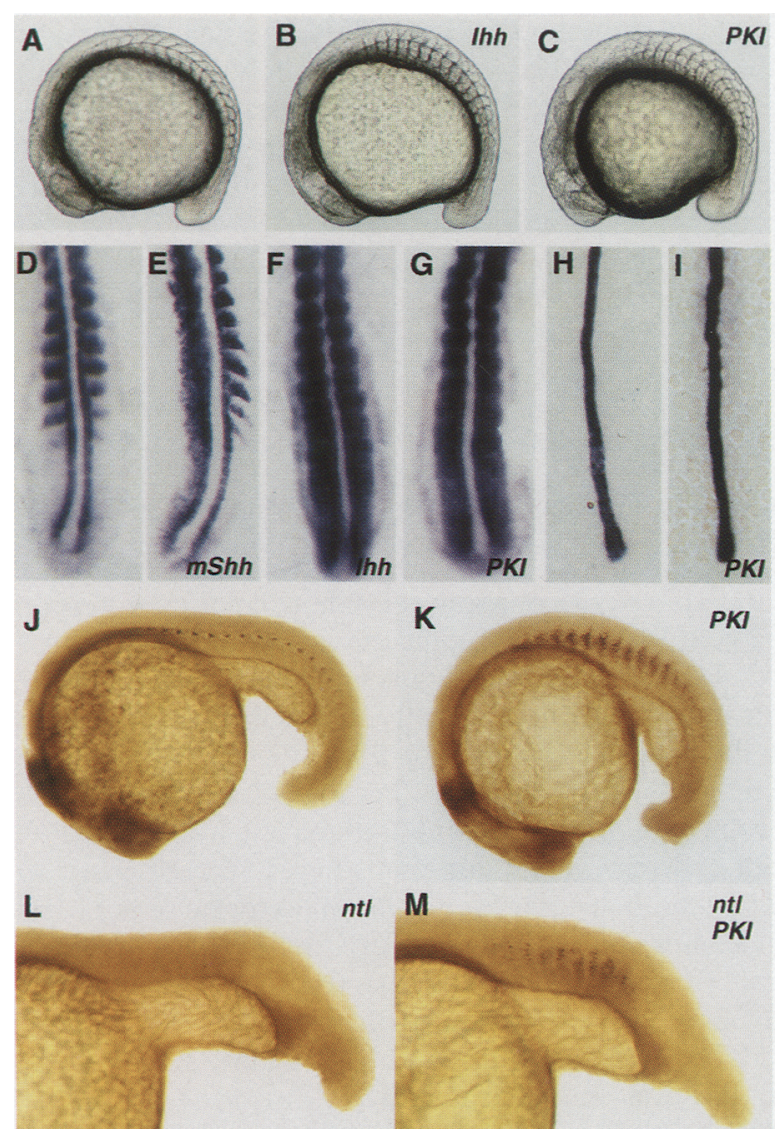

Figure 3. The effect of expression of $h$ h family members and PKI on the specification of the myotome in wild-type and $n t I$ mutant embryos. $(A-C)$ Fifteen-somite-stage embryos, lateral view. $(D-I)$ Fifteen-somite-stage embryo, dorsal view of posterior part of axis; $(D-G)$ expression of myoD; $(H, I)$ expression of shh. $(J, K)$ Expression of en in 25-somite-stage embryo, lateral view. $(L, M)$ Expression of en in $n t l$ embryos at 30 -somite stage, lateral view of tail region.

of the notochord. In contrast to the chick and mouse, the sclerotome of young zcbrafish somites is much smaller than the myotome and is located in ventral medial positions at some distance from the notochord (Kimmel et al. 1995). The positions of the paraxial mesoderm adjacent to the notochord are occupied by a specific subset of myotomal cells that express myoD (Weinberg et al. 1996) in the presomitic mesoderm. After somite formation, these adaxial cells give rise to the muscle pioneer cells, which can be identified by their enhanced expression of a zebrafish engrailed gene (en; Hatta et al. 1991a). It is likely that induction of the muscle pioneers is dependent on notochordal signals as these cells are lost in no tail (ntl) mutants in which the notochord precursors fail to differentiate (Halpern et al. 1993; Schulte-Merker et al. 1994).

To address the role of Hh signaling in zebrafish somite patterning, we injected RNAs encoding various hhs and PKI. Embryos injected with zebrafish $s h$, mouse Shh or Ihh, and PKI display a clear somitic phenotype. At the 15-somite stage, somites do not form the normal chevron shape (Fig. 3A-C), and in a smaller proportion of the embryos, the horizontal myoseptum, which lies at the midline of the dorsal-ventral axis of the somite at later stages of development, is irregular. In the presomitic mesoderm, myoD expression, which is normally restricted to the adaxial mesoderm immediately adjacent to the notochord, extends laterally over the entire width of the presomitic mesoderm (mShh: 30 of 48, 62\%; Ihh: 28 of $51,55 \%$; PKI: 22 of $25,88 \%$ ) (Fig. 3D-G). Consequently, there is a corresponding increase in en-expressing muscle pioneers. Instead of five to six per somite as observed in uninjected control embryos, or controls injected with lacZ RNA (35 of 35), embryos ectopically expressing $I h$ h have $\leqslant 15$ (mShh: 18 of $27,67 \%$; Ihh: 41 of $57,72 \%$ ), and those expressing PKI as many as 30 muscle pioneer cells per somite ( 58 of $82,71 \%$ ) (Fig. $3 \mathrm{~J}, \mathrm{~K}$; data not shown). Moreover, these en-expressing cells are dispersed over the entire mediolateral width of the somite, whereas in uninjected embryos they are excusively medial (Fig. 4I). Thus, ectopic expression of hh family members and PKI leads to an expansion of medial muscle cell fate in the paraxial mesoderm.

myoD expression is also expanded in the somites themselves, most dramatically in PKI-injected embryos, consistent with an enlargement of the myotome (Fig. 3D-G). As we detect no ectopic expression of the endogenous shh gene in caudal regions of PKI-injected embryos $(0$ of 25 ; Fig. $3 \mathrm{H}, \mathrm{I})$, the activation of targets of the Hh signaling pathway occurs in the apparent absence of a Hh signal.

The finding that ectopic Shh, Ihh, and PKI induce the formation of extra muscle pioneers in wild-type embryos suggests that the reduction of a Hh signal might be the reason for the somite alterations in $n t l$ mutant embryos. Although ntl mutants show some myoD staining in adaxial positions of the presomitic mesoderm, En-positive muscle pioneers never form (Halpern et al. 1993). Injection of mRNA encoding Ihh or PKI leads to a broadening of the adaxial expression of myoD in the presomitic mesoderm of ntl mutants (Ihh: 6 of $8,75 \%$; PKI: 5 of $6,83 \%$; data not shown). Moreover, in $80 \%$ of the PKI-injected ntl mutants, En-positive muscle pioneer cells are observed at later stages of development (10 of 12; Fig. 3L,M). Therefore, suppressing PKA activity in target cells can rescue the defects that result from the loss of Hh signaling by the notochord. Interestingly, we failed to rescue muscle pioneers by injection of Ihh mRNA. Thus, although Ihh can activate $m y o D$ expression in the absence of the notochord, it does not appear to be sufficient for the induction of muscle pioneers.

We also examined twist (Yan et al. 1995) expression in $h h$ and PKI-injected embryos. twist is expressed in both the sclerotome and the hypochord, a prominent midline rod-like structure of unknown function that lies immediately beneath the notochord in the fish embryo. twist expression is lost or reduced strongly in presumptive sclerotomal cells in ventromedial positions within the somite (Ihh: 8 of 14, 57\% ; PKI: 27 of 36, 75\%; Fig. 4A,B; data not shown). Remaining twist expression is re- 


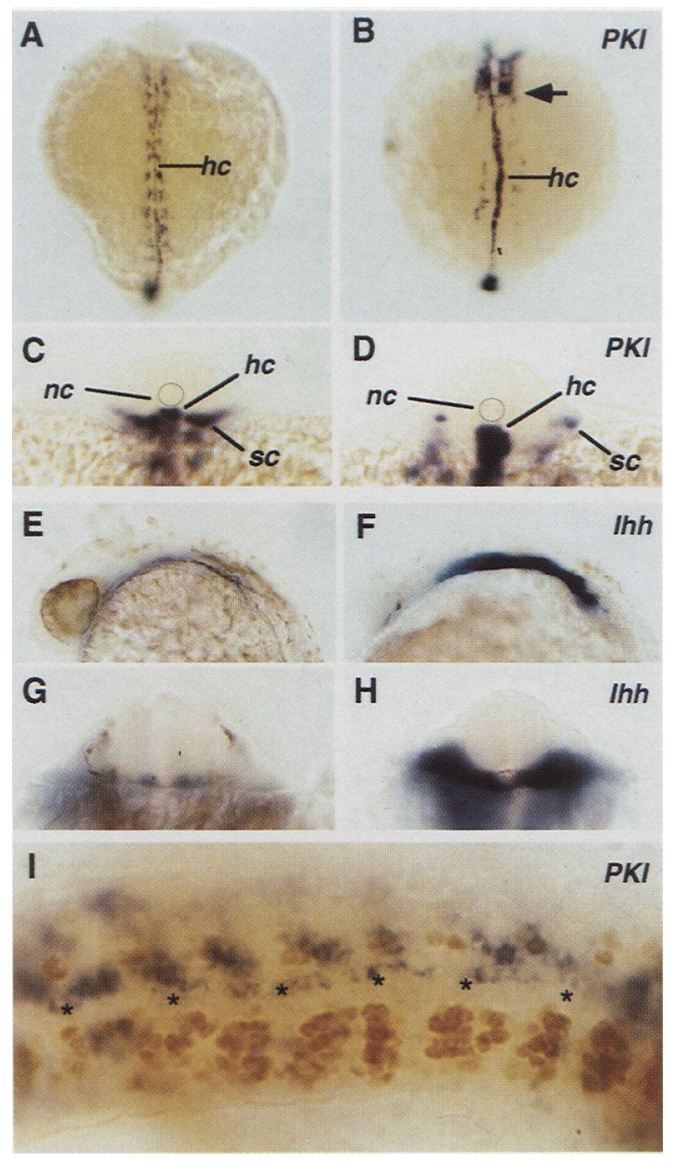

Figure 4. The effects of expression of $h h$ family members and PKI on expression of twist in the sclerotome, head mesenchyme, and hypochord. $(A-D) 20$-somite stage; $|A, B|$ dorsal view; $(C, D)$ optical cross-section at level of tenth somite; the notochord is outlined. In $B$, note the abrupt change in the response of twist expression at the level of the first somite, indicated with an arrow. In $B$ and $D$, the enhanced midline expression of $t$ wist in PKI-injected embryos represents hypochordal expression. $(E-H)$ Thirty-hour-old embryos; $(E, F)$ lateral view of head; $(G, H)$ optical cross-section at level of hindbrain. $(I)$ Double-labeling of twist mRNA (blue) and En protein (brown) in a 25-somite-stage PKI-injected embryo that is only affected on one (lower) side; dorsal view. The stained hypochord in the ventral midline is marked by asterisks. (hc) Hypochord; (nc) notochord; (sc) sclerotome.

stricted to ventrolateral positions (Fig. 4C,D). The coincidence of the loss of sclerotomal and the gain of adaxial myotomal specification is revealed clearly in double-labeled embryos in which only one side of the axis is affected, presumably because of the asymmetric localization of the injected RNA /Fig. 4I, see Materials and methods). These findings suggest that high concentrations of $\mathrm{Hh}$ and PKI promote myotomal and repress sclerotomal specification in zebrafish somites. In contrast to the sclerotome of the trunk, twist expression is up-regulated in the hypochord (Fig. 4A-D).

Many studies have addressed the inductive properties of notochordal signals on presomitic mesoderm. How- ever, the notochord extends into the head, where it is surrounded by head mesenchyme. In wild-type zebrafish embryos, adaxial cells of the head mesenchyme adjacent to the notochord express twist. This expression is increased strongly and expanded laterally in embryos injected with Ihh or PKI mRNA (Ihh: 32 of $47,68 \%$; PKI: 43 of $59,73 \%$; Fig. 4A,B, E-H). Thus, Hh signaling may have a role in patterning the head mesenchyme, and as in all other sites studied, this induction is mimicked by suppression of PKA.

\section{A constitutively active form of $P K A$ represses structures that are promoted by Ihh and PKI}

If PKA is a negative regulator of $\mathrm{Hh}$ signaling in responding cells, we would predict that stimulation of PKA activity should suppress endogenous Hh signaling. To test this model, we injected mRNA encoding a mutated form of the catalytic subunit of PKA (PKA*), which is rendered constitutively active because of a reduced affinity for the regulatory subunit (Orellana and McKnight 1992).

In contrast to the dominant-negative regulatory subunit, zebrafish embryos display an extreme sensitivity to the expression of the constitutively active catalytic subunit. Almost all embryos injected with 100 pg of RNA encoding PKI and Ihh survive, whereas all those injected with the same amount of RNA encoding PKA* die during blastula and gastrula stages. Lowering the mass of RNA injected enhances embryo survival $190 \%$ survive postgastrulation after injection of $5 \mathrm{pg}$ of mRNA), and having passed the critical early stages, surviving embryos exhibit no increase in lethality. Approximately half (19 of 36) of these display a common phenotype: fused eyes (Fig. 5A,B), a short and laterally curved body axis and somites that lack their horizontal myoseptum (Fig. 5C,D). Both the notochord and the floor plate appear normal.

Similar to $c y c$ mutant embryos, which lack midline shh expression, pax2 expression in the optic stalk is greatly reduced or completely missing at the 15 -somite stage of PKA*-injected embryos (61 of 82, 74\%; Fig. $5 \mathrm{E}, \mathrm{F})$. At early pharyngula stages, some pax 2 expression can be detected in the forebrain of injected embryos; however, this expression remains at the midline rather than being split into two domains defining the proximal region of the developing eyes ( 47 of $62,76 \%$; Fig. 5G,H). In addition, the expression domains of pax6, which normally define distal regions of the eye vesicles, are shifted toward the midline ( 28 of $35,80 \%$; Fig. $5 \mathrm{I}, \mathrm{J})$.

As in cyc mutant embryos, the loss of pax2 expression and fusion of the eyes in PKA*-injected embryos might be a secondary consequence of the failure of ventral midline specification in the forebrain. In agreement with this interpretation, the normal forebrain extension of shh $(14$ of $25,56 \%$; Fig. $5 \mathrm{~K}, \mathrm{~L})$ and otx $2(14$ of $20,70 \%$; Fig. $5 \mathrm{M}, \mathrm{N})$ expression is not observed in PKA*-injected embryos. Thus, Shh signaling may be required for normal ventralization of the forebrain, acting, at least in part, as an autoinductive signal. 

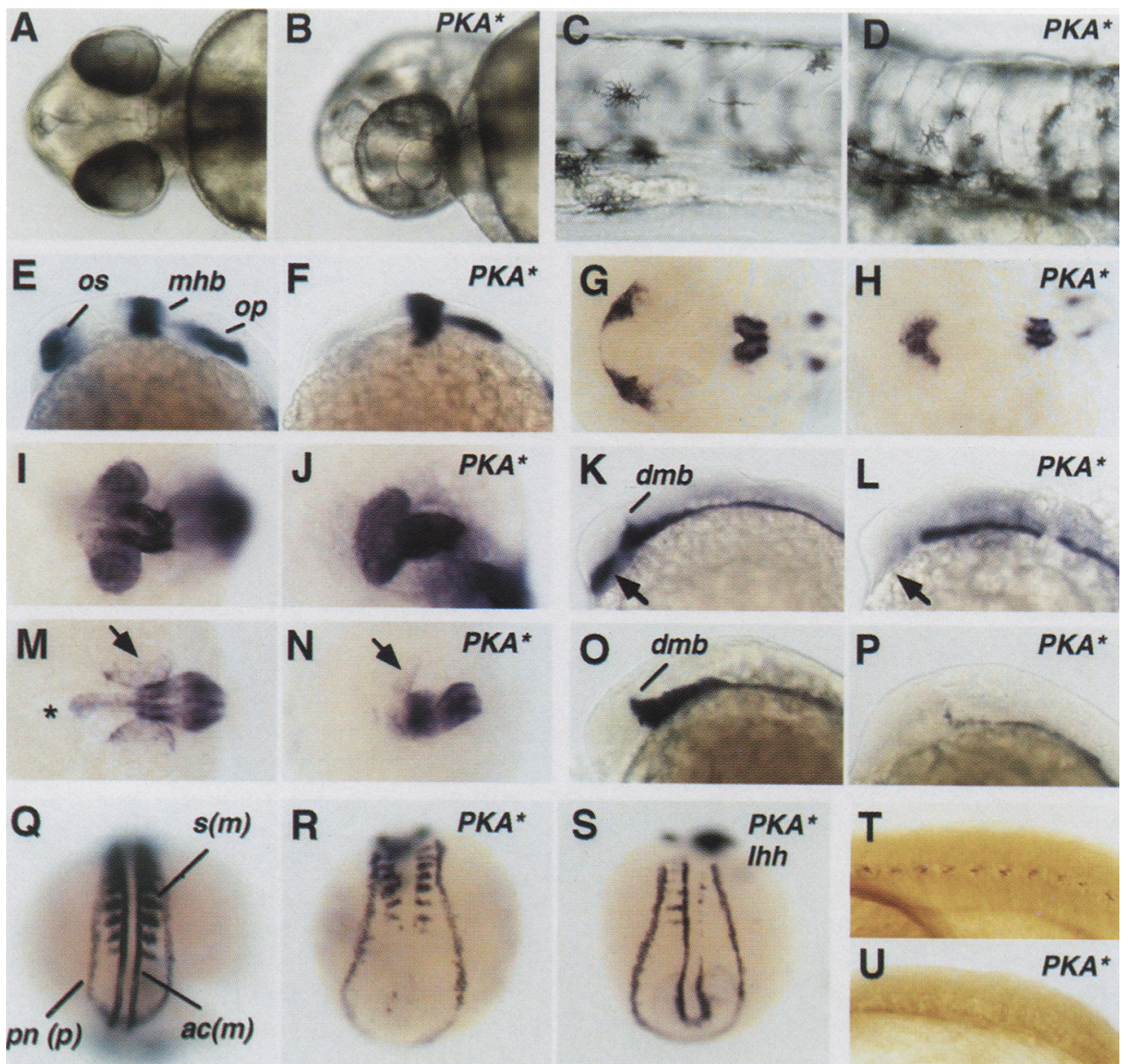

Figure 5. Expression of $\mathrm{PKA}^{*}$ suppresses ectopic and endogenous Hh signaling. $(A, B)$ Forty-eight-hour-old embryo, ventral view of head. $(C, D)$ Seventy-two-hour-old larvae, lateral view of trunk somites. $(E-H)$ Expression of pax2. $(E, F)$ Fifteen-somite stage, lateral view of head. $(G, H)$ Twenty-four-hour-old embryos, dorsal view of head. $(I, I)$ Expression of pax6 in a 24-hr-old embryo, dorsal view of head. $(K, L)$ Expression of $s h$ in 24-hour-old embryos, lateral view of head. shh expression in the ventral forebrain is indicated by an arrow. $(M, N)$ Expression of otx2 in a 30-hour-old embryo, dorsal view of head. $(M)$ otx2 expression in the ventral forebrain is indicated by an asterisk; $(M, N)$ otx2 expression in proximal regions of the eyes is indicated by an arrow. $(O, P)$ Expression of axial in 24-hr-old embryos, lateral view of head. $(\mathrm{Q}-S)$ Expression of $m y o D(m)$ and $p a x 2(p)$ in a 15-somite-stage embryo, dorsal view of posterior trunk. (S) PKA* and $I h$ h coinjected. $\{T, U)$ Expression of $e n$ in 24-hr-old embryos, lateral view of trunk. (ac) Adaxial cells; (dmb) diencephalicmesencephalic boundary; (mhb) midbrain-hindbrain boundary; (op) otic placode; (os) optic stalk; (pn) pronephros.

At the mid/hindbrain level, ventral expression of shh appears unaltered. In contrast, expression of axial is reduced but never absent completely 38 of $56,68 \%$; Fig. $5 \mathrm{O}, \mathrm{P})$. In the floor plate of the spinal cord, expression of shh and axial are normal (data not shown) and dorsal midline expression of wnt1 throughout the CNS is unaffected (16 of 16; data not shown). Thus, stimulation of PKA activity leads to ventral-specific defects in anterior CNS patterning that are consistent with the suppression of endogenous Hh signaling.

In the mesoderm, adaxial myoD expression in presomitic mesoderm is also missing at early somite stages (57 of $73,78 \%$; Fig. 5Q,R), with an accompanying loss of en-expressing muscle pioneers at later stages $(26$ of 28 , $93 \%$; Fig. 5T,U). Furthermore, myoD expression in the somites is reduced greatly. In summary, structures that are affected by ectopic expression of $h h$ genes and PKI are also modulated by $\mathrm{PKA}^{*}$, but with opposite results. Thus, specification of proximal fates in the eyes, ventral fates in the brain, and medial muscle fates in the somites are promoted by ectopic expression of $h h$ s and inactivation of PKA, but suppressed by activation of PKA.

To determine whether PKA is epistatic to Hh signals, as would be expected from our analysis, we examined the effects of coinjection of shh, Ihh, and PKA* mRNA on patterning of the eyes, brain, and presomitic mesoderm. Even when $h$ h RAs are injected in a 10- to 100fold molar excess, no ectopic pax2, myoD, or axial expression is observed. Moreover, the endogenous expression domains of these target genes are suppressed as also observed in embryos injected with PKA* mRNA alone (Fig. 5Q-S; Table 1). 
Hammerschmidt et al.

Table 1. Coinjection of constitutively active PKA* and Hhs

\begin{tabular}{lcccccc}
\hline Phenotype & $\begin{array}{c}\text { zfShh }(40 \mathrm{pg}) \\
+ \text { PKA }^{*}(4 \mathrm{pg})\end{array}$ & $\begin{array}{l}\text { zfShh } \\
(40 \mathrm{pg})\end{array}$ & $\begin{array}{l}\mathrm{PKA}^{*} \\
(4 \mathrm{pg})\end{array}$ & $\begin{array}{c}\text { Ihh }(200 \mathrm{pg}) \\
+\mathrm{PKA}^{*}(2 \mathrm{pg})\end{array}$ & $\begin{array}{l}\text { Ihh } \\
(200 \mathrm{pg})\end{array}$ & $\begin{array}{l}\text { PKA* } \\
(2 \mathrm{pg})\end{array}$ \\
\hline Ectopic myoD & $0 / 27(0 \%)$ & $15 / 24(62 \%)$ & $0 / 26(0 \%)$ & $0 / 28(0 \%)$ & $22 / 38(59 \%)$ & $0 / 26(0 \%)$ \\
Loss of myoD & $7 / 27(26 \%)$ & $0 / 24(0 \%)$ & $13 / 26(50 \%)$ & $15 / 28(54 \%)$ & $0 / 38(0 \%)$ & $22 / 26(85 \%)$ \\
Ectopic pax2 & N.D. & N.D. & N.D. & $0 / 46(0 \%)$ & $36 / 38(95 \%)$ & $0 / 26(0 \%)$ \\
Loss of pax2 & & & $34 / 46(74 \%)$ & $0 / 38(0 \%)$ & $23 / 26(88 \%)$ \\
Ectopic axial & $0 / 20(0 \%)$ & $14 / 23(61 \%)$ & $0 / 16(0 \%)$ & N.D. & N.D. & N.D. \\
Loss of axial & $10 / 20(50 \%)$ & $0 / 23(0 \%)$ & $16 / 16(100 \%)$ & & \\
\hline
\end{tabular}

Sibling embryos were either injected with $h$ RNA, or with PKA* RNA or with both, and were stained for myoD (in the presomitic mesoderm) or pax2 RNA (in the promimal regions of the eyes) at the 20-somite stage, or for axial RNA (in the ventral base of the brain) at $26 \mathrm{hr}$ of development.

(N.D.) Not done.

\section{Discussion}

Hh signaling is mimicked by repression of PKA

Our studies point to an evolutionarily conserved role for PKA as a negative regulator of the $\mathrm{Hh}$ signaling pathway. Ectopic expression of PKI, a potent dominant-negative regulatory subunit of $\mathrm{PKA}$, leads to alterations in the patterning of the brain, eyes, and somites that mimic the effects of ectopic expression of several hh family members. In all cases, the responsive cells lie in close proximity to normal sites of $s h$ expression in midline cell populations. In contrast, ectopic expression of a constituitively active form of PKA suppresses completely the effects of ectopic $\mathrm{Hh}$ signaling and partially suppresses the targets of endogenous $\mathrm{Hh}$ signaling. Thus, PKA is epistatic to Hh signals.

In general, the results are consistent with a simple model: Hh signaling by midline structures (the notochord and ventral CNS) acts on neighboring cells to overcome a PKA-mediated inhibition of $\mathrm{Hh}$ target genes. The signal may be Shh, or other midline-expressed family members. An alternative explanation, that PKI-mediated pattern alterations are a secondary consequence of the activation of endogenous shh expression, seems unlikely for a number of reasons. For example, we fail to observe significant ectopic expression of shh in PKI-injected embryos despite the dramatic expansion of pax2 expression in the eye, axial expression in the brain, and myoD and en expression in the muscle pioneers and myotome of the somites. Furthermore, pax 2 expression in the eye primordium and en expression in muscle pioneers are rescued by $\mathrm{PKI}$ injection in $c y c$ and $n t l$ mutants, respectively, although these mutants lack the normal sites of Shh synthesis that are associated with the induction of these markers. Thus, increased Shh production by the normal midline signaling centers does not appear to be responsible for the PKI-mediated activation of $\mathrm{Hh}$ target genes. Rather, as has been observed in PKA-deficient clones in Drosophila imaginal discs (Li et al. 1995), PKImediated activation of $\mathrm{Hh}$ targets is most likely cell autonomous and $\mathrm{Hh}$ independent.

Interestingly, zebrafish embryos expressing PKI have no additional phenotypes compared with those ectopically expressing hhs. Thus, a major early role of PKA in the fish appears to be the modulation of $\mathrm{Hh}$ signaling. This function is conserved in other vertebrates. For example, in the mouse, ectopic expression of Shh and PKI in the CNS both lead to the ectopic transcriptional activation of $H N F-3 \beta$, an axial-related gene, whose expression is normally restricted to the ventral midline. Furthermore, Patched, which codes for a transmembrane protein whose Drosophila ortholog is regulated by $\mathrm{Hh}$ and PKA, is ectopically transcribed (Echelard et al. 1993; Goodrich et al. 1996; D.J. Epstein, E. Martí, M.P. Scott, and A.P. McMahon, in prep.). Moreover, our observation that Ihh has similar inductive properties to Shh, and that signaling can be blocked by PKA*, suggests that Ihh, and possibly other Hh family members, may also act through a similar pathway. At present it is not clear whether PKA is directly in the $\mathrm{Hh}$ signaling pathway, or has an indirect role, modulating the activity of a common target (Kalderon 1995; Perrimon 1995). However, the observation that suppression of ectopic Hh signaling by $\mathrm{PKA}^{\star}$ is not overridden by an excess of Hh signal supports the view that PKA acts downstream of Hh signals in a linear pathway. A satisfactory resolution of this issue will require the identification of $\mathrm{Hh}$ receptors and a more thorough characterization of $\mathrm{Hh}$ signaling pathways.

\section{Differential responses of the neuroectoderm to Hh signals}

An interesting characteristic of Hh- and PKI-injected embryos is that ectopic expression of axial is limited to defined regions along the anteroposterior and dorsoventral axes. No ectopic axial expression is observed in the forebrain, which lies anterior to the position where normal axial expression ends in the CNS. Thus, this boundary is not set by an anterior limit to Hh signaling but by the inability of forebrain cells to respond to the Hh pathway in the same way as their midbrain neighbors. These results indicate that prior anterior-posterior patterning within the CNS dictates the response to Hh signaling. Furthermore, the profile of ectopic axial expression in the midbrain and hindbrain in response to zebrafish Shh and PKI is almost identical. Thus, the competence of these target cells to respond to Hh signaling may not be 
limited by the distribution of a $\mathrm{Hh}$ receptor but by a component of the signal transduction pathway downstream of PKA, such as a transcription factor whose activity is regulated by PKA-mediated phosphorylation.

Surprisingly, ventral development of the spinal cord is unaffected in embryos injected with RNAs encoding various Hhs, PKI, or $\mathrm{PKA}^{*}$, although the presomitic mesoderm at a similar axial level shows a strong response. This is in contrast to findings in vitro where explants of intermediate trunk neuroectoderm show a concentration dependent response to Shh signaling, inducing either floor plate (high concentration) or motor neuron (lower concentration) markers (Roelink et al. 1995). The different outcome of our experiments may have a trivial explanation. For instance, the induction of floor plate may occur later than adaxial specification in the presomitic mesoderm, so that the floor plate in the posterior spinal cord is less affected because of the progressive degradation of the injected synthetic RNA. However, we cannot rule out differences in the competence of the spinal cord to respond to a $\mathrm{Hh}$ signaling pathway in vivo versus in vitro. Furthermore, it is not clear whether differential suppression of endogenous PKA activity can lead to the induction of floor plate and motor neurons as separate events, as might be expected if PKA is a direct component of Hh signaling pathways.

\section{Hh signaling in the zebrafish and other vertebrates}

Our results raise some interesting questions about the evolution of Hh signaling in the development of different vertebrate structures. In all vertebrates examined, $S h h$ is expressed at the midline along the whole length of the body axis. In addition, the fish has at least two additional members, twhh (Ekker et al. 1995b) and moonrat hedgehog (P. Ingham, pers. comm.) that are expressed in either the notochord or floor plate. We observed a response of neighboring tissues to the overexpression of $h h$ s and the suppression or hyperactivation of PKA at all axial levels, consistent with a role for Shh, and possibly other midline expressed Hh family members, in the regulation of several different components of the early body plan.

In the brain, Shh promotes proximal specification in the eye premordia in the forebrain and ventralization of the CNS in the midbrain and hindbrain (Echelard et al. 1993; Krauss et al. 1993; Ekker et al. 1995b; Macdonald et al. 1995). Also in the head, notochordal Hh signaling may regulate adaxial specification in the head mesenchyme. In the trunk and tail, Hhs from the notochord appear to promote the specification of the hypochord, a midline structure lying ventral to the notochord in fish and amphibians, whose origin and function are poorly understood. Mammals and birds do not appear to have a hypochord. In addition, in the paraxial trunk mesoderm, Hh signaling promotes adaxial specification of muscle pioneers, a second cell type not found in chicks and mice, and myotomal specification of the somites.

Although the effects we detect for Hhs in the brain are consistent with results obtained in the mouse (Echelard et al. 1993), our observations on paraxial mesoderm pat- terning appear to conflict with results obtained in chicken and mouse experiments (Johnson et al. 1994; Fan et al. 1995). However, when considered in the context of vertebrate evolution from simple chordate ancestors, together with the architecture of different vertebrate body plans, the various results are consistent.

In chick embryos in ovo and in explants of mouse presomitic mesoderm, Shh has been shown to activate sclerotomal- and to repress dermatomal-specific gene expression (Johnson et al. 1994; Fan et al. 1995). Thus, the most ventral component of the somite, the sclerotome, which lies immediately adjacent to the Shh expressing notochord, appears to require Shh signaling for its development. In addition, Shh also induces the expression of the myotome-specific gene myoD in the chick and mouse (Johnson et al. 1994; Münsterberg et al. 1995). As the myotome develops at a more dorsal position within the somite than the sclerotome, this would suggest an even more extensive long-range interaction between the somite and Shh produced by midline cells. Surprisingly, the induction of myoD expression in vitro requires higher concentrations of Shh than the induction of sclerotome-specific gene expression (Münsterberg et al. 1995). Moreover, chick embryos after notochord removal (Pourquie et al. 1993) and notochordless mouse mutants (HNF-3ß; Ang and Rossant 1994; Weinstein et al. 1994) still undergo myotomal development. Thus, although the myotome responds to Shh in chick and mice, Shh is not absolutely essential for its formation.

In contrast to amniotes, lower vertebrates such as the zebrafish have a quite different arrangement of somite derivatives. The sclerotome is proportionally much smaller, restricted to a medial position several cell diameters away from the notochord. In contrast, the large myotome abuts the notochord, and myotomal cells in contact with the notochord give rise to muscle pioneers. It is thought that the chordate ancestor of the vertebrates, like existing chordates such as Amphioxus, lacked sclerotome and, as a consequence, vertebrae, but still developed a large paraxial myotome adjacent to the notochord. Thus, sclerotomal development in the trunk is a recent vertebrate acquisition.

We suggest the following interpretation of the various observations. The initial function of $\mathrm{Hh}$ signaling in vertebrates was the induction of muscle development, which may have required different concentrations of $\mathrm{Hh}$ signals for different cell types, as has been observed in the ventral CNS (Roelink et al. 1995). Thus, muscle pioneers that develop in contact with the notochord may require higher concentrations of $\mathrm{Hh}$, whereas more general myotome induction may require lower concentrations. The evolution of sclerotome presumably occurred when somitic cells evolved a new competence to respond to midline $\mathrm{Hh}$ signals but at some distance from the source. Therefore, sclerotome cells presumably required lower amounts of $\mathrm{Hh}$ for their induction than the adaxial muscle cells. Consistent with the view that different concentrations of $\mathrm{Hh}$ are required for positioning of somite derivatives, we observed that embryos injected with the constitutively active form of PKA showed some 
decrease in the expression of twist in the sclerotome, whereas adaxial expression of myoD and en were lost almost completely (M. Hammerschmidt and A.P. McMahon, unpubl.). Clearly, if expression of $\mathrm{PKA}^{\star}$ only partially blocks Hh signaling, those cells that require the highest concentration of signal will be most susceptible to PKA *-mediated inhibition. Thus, PKA seems to act as a negative regulator of the $\mathrm{Hh}$ signaling pathway in both short- and long-range signaling processes. A moderate inhibition of PKA presumably leads to induction of sclerotomal gene expression and a strong inhibition to the induction of myotomal gene expression.

A second feature of vertebrate evolution is the development of a head skeleton from the cranial neural crest (Noden 1988). Our results suggest that cranial crest cells, which migrate to and surround the anterior notochord, also respond to Hh signals, activating twist expression. Thus, during vertebrate evolution, Hh signaling may have had a pivotal role as a common mechanism for the initiation of cartilaginous development in the head mesenchyme and sclerotome. In summary, the induction of muscle precursors might be the phylogenetically older function of $\mathrm{Hh}$ signaling, which later in evolution was complemented by an induction of vertebrae and head skeleton structures. The shift in the structure of the somites from myotome to sclerotome as the predominant adaxial component might have been accomplished by modifications in the dependence of the two structures on Hh signals. In the chick, for instance, Shh can only induce myoD expression in collaboration with Wnt signals, which most likely are generated by the dorsal ectoderm (Münsterberg et al. 1995).

\section{Materials and methods}

\section{Expression constructs}

cDNAs for in vitro transcription were cloned into the BglII site of the plasmid pSP64T (Krieg and Melton 1984). The following cDNA fragments were used. (1) Zebrafish Shh, see Krauss et al. (1993) (pSP64T-zfShh). (2) Mouse Shh, full-length cDNA containing $\sim 250 \mathrm{bp}$ of $5^{\prime}$ and $3^{\prime}$ untranslated region (UTR), respectively (pSP64T-mShh) (Bumcrot et al. 1995). (3) Mouse Ihh, a 1.2-kb fragment of full-length Ihh cDNA obtained by a complete SmaI and a partial BamHI digest, containing the coding region plus 15 bp of $5^{\prime}$ UTR and 40 bp of $3^{\prime}$ UTR (pSP64T-Ihh). (4) Constitutively active PKA catalytic subunit PKA*, a $1.15-\mathrm{kb}$ NcoI-ApaI fragment of plasmid pCQ87/R196 (a gift of G.S. McKnight, cf. Orellana and McKnight 1992) (pSP64T-PKA*). (5) Dominant-negative PKA regulatory subunit PKI, plasmid pMT$\mathrm{Rev}^{\mathrm{AB}}$ neo (a gift of G.S. McKnight, cf. Clegg et al. 1987), was digested with $\mathrm{XbaI}$ and resealed to remove the metallothionine promotor. A 1.4-kb fragment of the religated vector obtained by a partial Pst digest that contains the coding region of the mutated regulatory subunit plus $30 \mathrm{bp}$ of 5' UTR and 20 bp of 3' UTR was cloned into Bluescript, and a 1.4-kb fragment obtained by a complete EcoRV and partial Sma digest of this construct was cloned into pSP64T (pPSP64T-PKI).

Formation of synthetic MRNA and injection of embryos

The plasmids pSP64T-Shh and pSP64T-Ihh were linearized with Sall, pSP64T-PKI, and pSP64T-zfShh with BamHI, and pSP64T-PKA* with XbaI. Capped mRNA was synthesized us- ing the SP6 message machine kit (Ambion, Texas) according to suppliers' instructions. The quality of the synthetic RNA was determined by ethidium-agarose gel electrophoresis, and the concentration determined spectrometrically. All RNAs generated the expected protein products when translated in a rabbit reticulocyte lysate (GIBCO/BRL).

For injection into embryos, the diluted RNA solutions were supplemented with Phenol red (Sigma; final concentration of $0.05 \%$ / to allow a visual control of the injection process. Embryos were injected with $\sim 2 \mathrm{nl}$ of the RNA solution (100 pg, unless stated otherwise) using an Eppendorf microinjector 5242. Normally, the RNA was injected into the center of the yolk of one- to four-cell-stage embryos. Following the cytoplasmic streaming, the RNA is transported very rapidly to the animal pole of the embryo and rather uniformly distributed in all cells, as demonstrated by in situ hybridization at various blastula and gastrula stages (data not shown). In some cases, the RNA was injected into single blastomeres of four- to eight-cell embryos or into the yolk right underneath the blastomeres. RNA supplied this way stays restricted to the injected cells and their descendants, as revealed by in situ hybridization and immunostainings at late blastula stages (data not shown). This often leads to embryos that show the ectopic expression restricted to the left or right half of the embryo, with a sharp border in the dorsal midline (data not shown), thereby providing a negative control in the same embryo.

Previous studies with other mRNAs had shown that $\sim 95 \%$ of the synthetic mRNA injected into one- to four-cell-stage embryos appeared full-length at the one-somite stage in Northern blot analyses (M. Hammerschmidt, unpubl.), suggesting that ectopic protein would be present at stages when Hh signaling is normally occurring. Mouse $S h h$ and $I h h$ were strongly expressed in injected zebrafish embryos at blastula and gastrula stages, as revealed by whole-mount immunostaining stages with an affinity-purified anti-mouse Shh antiserum (Martí et al. 1995b), which detects both mShh and Ihh but fails to detect endogenous zebrafish Hhs (data not shown).

\section{Fish maintainence, in situ hybridization, and} immunostaining

Fish were maintained and bred as described in Mullins et al. (1994). Whole-mount in situ hybridization and antibody stainings were carried out as described previously (Hammerschmidt and Nüsslein-Volhard 1993). Anti-En monoclonal antibody supernatant from 4D9 hybridoma cells (a gift of C. Dreyer, Max Planck Institüt für Entwicklungsbiologie, Tübingen, Germany) was diluted 1:1 with incubation buffer. For double-stainings, embryos underwent a standard in situ hybridization, followed by a fixation for 2-6 hr in $4 \%$ paraformaldehyde and a standard immunostaining.

\section{Acknowledgments}

We thank Dr. David Bumcrot for carrying out the initial steps in the construction of pSP64T-PKI. We are particularly grateful to Dr. G. Stanley McKnight for the gift of cDNAs encoding the dominant-negative regulatory and constitutively active catalytic PKA subunits, and to Dr. Phil Ingham for the expression construct pSP64T-zfShh. Drs. Bob Riggleman and Eric Weinberg generously supplied us with the zebrafish twist and myoD cDNA before publication. Published cDNAs and antibodies were received from Drs. Christine Dreyer, Vladimir Korzh, Stefan Krauss, Christiane Nüsslein-Volhard, Anders Molven, and Eric Weinberg. Work in A.P.M.'s laboratory was supported by a grant from the National Institutes of Health. M.H. was sup- 
ported by long-term European Molecular Biology Organization and Human Frontier Science Program Organization (HFSPO) Postdoctoral Fellowships.

The publication costs of this article were defrayed in part by payment of page charges. This article must therefore be hereby marked "advertisement" in accordance with 18 USC section 1734 solely to indicate this fact.

\section{Note added in proof}

Following submission of this paper, Weinberg et al. (1996) described an expansion of the presomitic myoD expression upon ectopic expression of zebrafish shh similar to results presented here.

\section{References}

Ang, S.-L. and J. Rossant. 1994. HNF-3ß is essential for node and notochord formation in mouse development. Cell 78: 561574.

Appel, B., V. Korzh, E. Glasgow, S. Thor, T. Edlund, I.B. Dawid, and J.S. Eisen. 1995. Motoneuron fate specification revealed by patterned LIM homeobox gene expression in embryonic zebrafish. Development 121: 4117-4125.

Basler, K. and G. Struhl. 1994. Compartment boundaries and the control of Drosophila limb pattern by hedgehog protein. $\mathrm{Na}$ ture 368: 208-214.

Bitgood, M.J. and A.P. McMahon. 1995. Hedgehog and Bmp genes are co-expressed at many diverse sites of cell-cell interaction in the mouse embryo. Dev. Biol. 172: 126-138.

Bitgood, M., L. Shen, and A.P. McMahon. 1996. Sertoli cell signaling by Desert hedgehog regulates the male germ line. Curr. Biol. (in press).

Brand-Saberi, B., C. Ebensperger, J. Wilting, R. Balling, and B. Christ. 1993. The ventralizing effect of the notochord on somite differentiation in chick embryos. Anat. Embryol. 188: 239-245.

Bumcrot, D.A. and A.P. McMahon. 1995. Sonic signals somites. Curr. Biol. 5: 612-614.

Bumcrot, D.A., R. Takada, and A.P. McMahon. 1995. Proteolytic processing yields two secreted forms of Sonic hedgehog. Mol. Cell. Biol. 15: 2294-2303.

Chang, D.E., A. Lopez, D.P. von Kessler, C. Chiang, B.K. Simandl, R. Zhao, M.F. Seldon, J.F. Fallon, and P.A. Beachy. 1994. Products, genetic linkeage, and limb patterning activity of a mouse hedgehog gene. Development 120:33393353.

Clegg, C.H., L.A. Corell, G.G. Cadd, and S. McKnight. 1987. Inhibition of intracellular cAMP-dependent protein kinase using mutant genes of the regulatory typeI subunit. $/$. Biol. Chem. 262: 13111-13119.

Echelard, Y., D.J. Epstein, B. St-Jauques, L. Shen, J. Mohler, J.A. McMahon, and A.P. McMahon. 1993. Sonic hedgehog, a member of a family of putative signaling molecules, is implicated in the regulation of CNS polarity. Cell 75: 14171430.

Ekker, S.C., L.L. McGrew, C.J. Lai, J.J. Lee, D.P. Von Kessler, R.T. Moon, and P.A. Beachy. 1995a. Distinct expression and shared activities of the hedgehog gene family of Xenopus laevis. Development 121: 2337-2347.

Ekker, S.C., A.R. Ungar, P. Greenstein, D.P. von Kessler, I.A. Porter, R.T. Moon, and P.A. Beachy. 1995b. Patterning activities of vertebrate hedgehog proteins in the developing eye and brain. Curr. Biol. 5: 944-955.
Ericson, J., J. Muhr, M. Placzek, T. Lints, T.M. Jessell, and T. Edlund. 1995. Sonic hedgehog induces the differentiation of ventral forebrain neurons: A common signal for ventral patterning within the neural tube. Cell 81: 747-756.

Fan, C.-M., J.A. Porter, C. Chiang, D.T. Chang, P.A. Beachy, and M. Tessier-Lavigne. 1995. Long-range sclerotome induction by Sonic Hedgehog: Direct role of the amino-terminal cleavage product and modulation by the cyclic AMP signaling pathway. Cell 81: 457-465.

Fietz, M.J., A. Jacinto, A.M. Taylor, C. Alexandre, and P.W. Ingham. 1995. Secretion of the amino-terminal fragment of the Hedgehog protein is necessary for hedgehog signalling in Drosophila. Curr. Biol. 5: 643-651.

Forbes, A.J., A.M. Taylor, Y. Nakano, and P.W. Ingham. 1993. Genetic analysis of hedgehog signalling in the Drosophila embryo. Development (Suppl.) 119: 115-124.

Goodrich, L.V., R.L. Johnson, L. Milenkovic, J.A. McMahon, and M.P. Scott. 1996. Conservation of the hedgehog/ patched signaling pathway from flies to mice: Induction of a mouse patched gene by Hedgehog. Genes \& Dev. 10: 301312 .

Halpern, M.E., R.K. Ho, C. Walker, and C.B. Kimmel. 1993. Induction of muscle pioneers and floor plate is distinguished by the zebrafish no tail mutation. Cell 75: 1-20.

Hammerschmidt, M. and C. Nüsslein-Volhard. 1993. The expression of a zebrafish gene homologous to Drosophila snail suggests a conserved function in invertebrate and vertebrate gastrulation. Development 119: 1107-1118.

Hatta, K., R. Bremiller, M. Westerfield, and C.B. Kimmel. 1991a. Diversity of expression of engrailed-like antigens in zebrafish. Development 112: 821-832.

Hatta, K., C.B. Kimmel, R.K. Ho, and C. Walker. 1991b. The cyclops mutation blocks specification of the floor plate of the zebrafish central nervous system. Nature 350: 339-341.

Heberlein, U., T. Wolff, and G.M. Rubin. 1993. The TGF $\beta$ homolog $d p p$ and the segment polarity gene hedgehog are required for the propagation of a morphogenetic wave in the Drosophila retina. Cell 75: 913-926.

Heemskerk, J. and S. DiNardo. 1994. Drosophila hedgehog acts as a morphogen in cellular patterning. Cell 76: 449-460.

Heynes, M., J.A. Porter, C. Chiang, D. Chang, M. TessierLevigne, P.A. Beachy, and A. Rosenthal. 1995. Induction of midbrain dopaminergic neurons by Sonic Hedgehog. Neuron 15: 35-44.

Ingham, P.W. 1993. Localized hedgehog activity controls spatial limits of wingless transcription in the Drosophila embryo. Nature 366: 560-562.

Ingham, P.W. and M.J. Fietz. 1995. Quantitative effects of hedgehog and decapentaplegic acitivity on the patterning of the Drosophila wing. Curr. Biol. 5: 432-440.

Ingham, P.W., A.M. Taylor, and Y. Nakano. 1991. Role of the Drosophila patched gene in positional signaling. Nature 353: 184-187.

Inoue, A., M. Takahashi, K. Hatta, Y. Hotta, and H. Okamoto. 1994. Developmental regulation of islet-1 mRNA expression during neuronal differentiation in embryonic zebrafish. Dev. Dyn. 199: 1-11.

Jiang, J. and G. Struhl. 1995. Protein kinase A and Hedgehog signaling in Drosophila limb development. Cell 80: 563572 .

Johnson, R.L., E. Laufer, R.D. Riddle, and C. Tabin. 1994. Ectopic expression of sonic hedgehog alters dorsal-ventral patterning of somites. Cell 79: 1165-1173.

Kalderon, D. 1995. Responses to Hedgehog. Curr. Biol. 5: 580582.

Kimmel, C.B., W.W. Ballard, S.R. Kimmel, B. Ullmann, and T.F. 
Schilling. 1995. Stages of embryonic development of the zebrafish. Dev. Dyn. 203: 253-310.

Korzh, V., T. Edlund, and S. Thor. 1993. Zebrafish primary neurons initiate expression of the LIM homeodomain protein Isll at the end of gastrulation. Development 118: 417-425.

Krauss, S., T. Johansen, V. Korzh, and A. Fjose. 1991. Expression pattern of zebrafish pax genes suggests a role in early brain regionalization. Nature 353: $267-270$.

Krauss, S., J.-P. Concordet, and P.W. Ingham. 1993. A functionally conserved homolog of the Drosophila segment polarity gene $h h$ is expressed in tissues with polarizing activity in zebrafish embryos. Cell 75: 1431-1444.

Krieg, P.A. and D.A. Melton. 1984. Functional messenger RNAs are produced by SP6 in vitro transcription of cloned cDNAs. Nucleic Acids Res. 12: 7057-7070.

Lepage, T., S.M. Cohen, F.J. Diaz-Benjumea, and S.M. Parkhurst. 1995. Signal transduction by cAMP-dependent protein kinase A in Drosophila limb patterning. Nature 373: 711-715.

Li, W., T. Ohlmeyer, M.E. Lane, and D. Kalderon. 1995. Function of protein kinase $\mathrm{A}$ in hedgehog signal transduction and Drosophila imaginal disc development. Cell 80: 553-562.

Li, Y., M.L. Allende, R. Finkelstein, and E.S. Weinberg. 1994. Expression of two orthodentical-related genes in the embryonic brain. Mech. Dev. 48: 229-244.

Ma, C., Y. Zhou, P.A. Beachy, and K. Moses. 1993. The segment polarity gene hedgehog is required for progression of the morphogenetic furrow in the developing Drosophila eye. Cell 75: 927-938.

Macdonald, R., K.A. Barth, Q. Xu, N. Holder, I. Mikkola, and S.W. Wilson. 1995. Midline signalling is required for Pax gene regulation and patterning of the eyes. Development 121: 3267-3278.

Martí, E., D.A. Bumcrot, R. Takada, and A.P. McMahon. 1995a. Requirement of $19 \mathrm{~K}$ form of Sonic Hedgehog for induction of distinct ventral cell types in CNS explants. Nature 375: 322-325.

Martí, E., R. Takada, D.A. Bumcrot, H. Sasaki, and A.P. McMahon. 1995b. Distribution of Sonic hedgehog peptides in the developing chick and mouse embryo. Development 121: 2537-2547.

Molven, A., P.R. Njølstad, and A. Fjose. 1991. Genomic structure and restricted neural expression of the zebrafish wnt-1 (int-1) gene. EMBO J. 10: 799-807.

Mullins, M.C., M. Hammerschmidt, P. Haffter, and C. Nüsslein-Volhard. 1994. Large-scale mutagenesis in the zebrafish: In search of genes controlling development in a vertebrate. Curr. Biol. 4: 189-202.

Münsterberg, A.E., J. Kitajewski, D.A. Bumcrot, A.P. McMahon, and A.B. Lassar. 1995. Combinatorial signaling by Sonic hedgehog and Wnt family members induces myogenic bHLH gene expression in the somite. Genes \& Dev. 9: 2911-2922.

Noden, D.M. 1988. Interactions and fates of avian craniofacial mesenchyme. Development 103:(Suppl.) 121-140.

Orellana, S.A. and S. McKnight. 1992. Mutations in the catalytic subunit of cAMP-dependent protein kinase result in unregulated biological activity. Proc. Natl. Acad. Sci. 89: 4726-4730.

Pan, D. and G.M. Rubin. 1995. cAMP-dependent protein kinase and hedgehog act antagonistically in regulating decapentaplegic transcription in Drosophila imaginal discs. Cell 80: $543-552$.

Perrimon, N. 1995. Hedgehog and beyond. Cell 80: 517-520.

Pourquie, O., M. Coltey, M. Teillet, C. Ordahl, and N.M. LeDouarin. 1993. Control of dorsoventral patterning of somitic derivatives by notochord and floor plate. Proc. Natl. Acad. Sci. 90: 5242-5246.

Riddle, R.D., R.L. Johnson, E. Laufer, and C. Tabin. 1993. Sonic hedgehog mediates the polarizing activity of the ZPA. Cell 75: 1401-1416.

Roelink, H., A. Augsburger, J. Heemskerk, V. Korzh, S. Norlin, A. Ruiz i Altaba, Y. Tanabe, M. Placzek, T. Edlund, T.M. Jessell, and J. Dodd. 1994. Floor plate and motor neuron induction by vhh-1, a vertebrate homolog expressed by the notochord. Cell 76: 761-775.

Roelink, H., J.A. Porter, C. Chiang, Y. Tanabe, D.T. Chang, P.A Beachy, and T.M. Jessell. 1995. Floor plate and motor neuron induction by different concentrations of the amino-terminal cleavage product of Sonic Hedgehog autoproteolysis. Cell 81: 445-455.

Saunders, J.W. and M. Gasseling. 1983. New insights into the problem of pattern regulation in the limb bud of the chick embryo. In Limb development and regulation, Part $A$ led. J.F. Fallon and A.I. Caplan), pp. 67-76. Alan R. Liss, New York, NY.

Schulte-Merker, S., F.V. Eeden, M.E. Halpern, C.B. Kimmel, and C. Nüsslein-Volhard. 1994. no tail (ntl) in the zebrafish homologue of the mouse $T$ (Brachyury) gene. Development 120: 1009-1015.

Strutt, D.I., V. Wiersdorff, and M. Mlodzik. 1995. Regulation of furrow progression in the Drosophila eye by cAMP-dependent protein kinase A. Nature 373: 705-709.

Tabata, T. and T.B. Kornberg. 1994. Hedgehog is a signaling protein with a key role in patterning Drosophila imaginal discs. Cell 76: 89-102.

Tanabe, Y., H. Roelink, and T.M. Jessell. 1995. Induction of motor neurons by Sonic hedgehog is independent of floor plate differentiation. Curr. Biol. 5: 651-658.

Wang, M.Z., P. Jin, D.A. Bumcrot, V. Marigo, A.P. McMahon, E.A. Wang, T. Woolf, and K. Pang. 1995. Induction of dopaminergic neuron phenotype in the midbrain by Sonic hedgehog protein. Nature Med. 1: 1184-1188.

Weinberg, E.S., M.L. Allende, C.S. Kelly, A. Abdelhamid, T. Murakami, P. Andermann, O.G. Duerre, D.J. Grunwald, and B. Riggleman. 1996. Developmental regulation of zebrafish myoD in wild-type, notail and spadetail embryos. Development 122: 271-280.

Weinstein, D.C., A. Ruiz i Altaba, W.S. Chen, P. Hoodless, V.R. Prezioso, T.M. Jessell, and J.E. Darnell Jr. 1994. The wingedhelix transcription factor $H N F-3 \beta$ is required for notochord development in the mouse embryo. Cell 78: 575-588.

Yamada, T., S.L. Pfaff, T. Edlund, and T.M. Jessell. 1993. Control of cell pattern in the neural tube: Motor neuron induction by diffusible factors from notochord and floorplate. CeIl 73: 673-686.

Yan, Y.-L., K. Hatta, B. Riggleman, and J.H. Postlethwait. 1995 Expression of a type II collagen gene in the zebrafish embryonic axis. Dev. Dyn. 203: 363-376. 


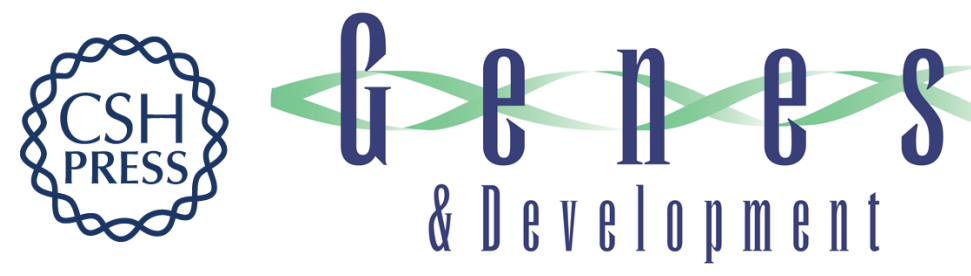

\section{Protein kinase $A$ is a common negative regulator of Hedgehog signaling in the vertebrate embryo.}

M Hammerschmidt, M J Bitgood and A P McMahon

Genes Dev. 1996, 10:

Access the most recent version at doi:10.1101/gad.10.6.647

References This article cites 63 articles, 18 of which can be accessed free at: http://genesdev.cshlp.org/content/10/6/647.full.html\#ref-list-1

License

Email Alerting Service right corner of the article or click here.

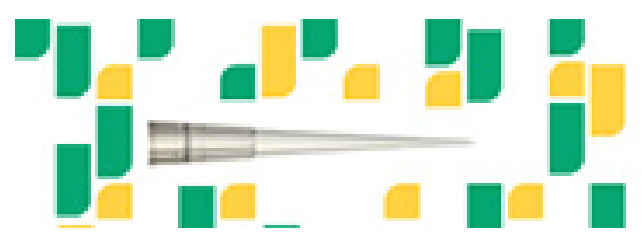

